\title{
Dual Binding Sites for Peanut Lectin on Rhizobia
}

\author{
By A. A. BHAGWAT AND JOSEPH THOMAS* \\ Biology and Agriculture Division, Bhabha Atomic Research Centre, \\ Trombay, Bombay 400 085, India
}

(Received 13 March 1979; revised 23 August 1979)

\begin{abstract}
Purified peanut lectin (peanut agglutinin, PNA) labelled with fluorescein isothiocyanate (FITC-PNA) or iodine-125 ( ${ }^{125}$ I-PNA) bound to Rhizobium B.TG-3 and Rhizobium 5 a, which nodulate peanut, but did not bind to $R$. japonicum or $R$. meliloti, which do not nodulate peanut, or to the non-nitrogen-fixing bacteria Escherichia coli and Bacillus subtilis. Washing the rhizobia in phosphate-buffered saline markedly decreased PNA binding. The decrease in binding could be correlated with removal of exopolysaccharides during washing. Dialysed culture filtrate could be labelled with ${ }^{125}$ I-PNA and the radioactivity was recovered in an acetone-precipitable exopolysaccharide fraction, showing that the lectin complexed with exopolysaccharides. Residual binding which remained after washing could not be removed by further washing. Moreover, rhizobia could be labelled with ${ }^{125}$ I-PNA after removal of exopolysaccharides and the radioactivity was recovered by extraction with hot phenol, indicating that the lectin complexed also with lipopolysaccharide on the bacterial cell wall. Rhizobial lipopolysaccharide not only inhibited haemagglutination by PNA but also dispersed preagglutinated human erythrocytes into free cell suspensions. The results demonstrate the presence of dual binding sites for PNA on rhizobia. Exopolysaccharides are the major sites and the remainder are lipopolysaccharides.
\end{abstract}

\section{INTRODUCTION}

Plant lectins, proteins characterized by their carbohydrate-binding property, are thought to be determinants in the host range specificity of microbial pathogens and of legumeRhizobium symbioses (Bauer, 1977). A number of recent studies have indicated that lectins are probably involved in the recognition of compatible rhizobia by their respective legume hosts. Bohlool \& Schmidt (1974) demonstrated that most of the rhizobia which nodulated soybean were also bound by soybean lectin, which had been labelled with fluorescein isothiocyanate (FITC), whereas the lectin did not bind to rhizobia incapable of nodulating soybean. A common antigen has been found (Dazzo \& Hubbell, 1975a) on the Rhizobium trifolii cell surface and clover root hair, indicating immunological specificity in the legumeRhizobium symbiosis. Trifoliin, an agglutinin purified from white clover by Dazzo et al. (1978), showed binding specificity towards its symbiont $R$. trifolii.

Evidence on the exact nature of the receptor sites for lectin binding on the bacterial cell surface has been conflicting. The binding site in the Rhizobium-clover symbiosis was shown to be sensitive to 2-deoxyglucose (Dazzo et al., 1976), which specifically inhibited the selective adsorption of $R$. trifolii capsular polysaccharide (exopolysaccharide) to receptor sites on clover root hairs (Dazzo \& Brill, 1977). The studies of Bhuvaneswari et al. (1977) indicated that in the soybean-Rhizobium system the biochemically specific lectin binding sites are transient components of the cell surface of $R$. japonicum. Subsequently, electron microscopic evidence favouring exopolysaccharides of $R$. japonicum as sites of soybean 
lectin binding was obtained in the same laboratory (Calvert et al., 1978). Wolpert \& Albersheim (1976), who isolated lectins from four different legumes that bound specifically to the respective rhizobia, found that the lectin interaction was with the bacterial lipopolysaccharides rather than with the capsular polysaccharides. Maier \& Brill (1978) found a surface antigen associated with the $\mathrm{O}$ antigen portion of the lipopolysaccharide in nodulating strains of $R$. japonicum but not in non-nodulating mutants.

Results suggesting lack of specificity in lectin binding have also been obtained (Dazzo \& Hubbell, 1975b; Chen \& Phillips, 1976). Recently, soybean lines lacking lectin have been reported to be effectively nodulated by $R$. japonicum strains (Pull et al., 1978).

The investigations cited above dealt mainly with the legume-Rhizobium symbioses in soybean and clover. We have examined the role of lectin in the peanut-Rhizobium symbiosis. Our experiments, using FITC- and ${ }^{125}$ I-labelled peanut agglutinin (PNA) show specificity in PNA binding to its rhizobial symbiont. The results indicate that there are dual binding sites on the Rhizobium cell surface, and afford a plausible interpretation for the apparently ambiguous results in the literature about the nature of receptor sites for lectin binding.

\section{METHODS}

Organisms. Rhizobium B.TG-3 was isolated from nodules of a arge pod mutant of Arachis hypogea developed at Trombay (Patil, 1973) called var. TG-3. Rhizobium $5 a$ is a peanut-nodulating strain provided by Dr Peter Dart, International Crops Research Institute for the Semi-Arid Tropics, Hyderabad, India. Escherichia coli K12 JC9239 was isolated by Mahajan \& Datta (1977) and Bacillus subtilis BS-40 by Kamat \& Kumta (1974) of this Research Centre.

Cultures. Stock cultures of the Rhizobium strains were stored at $4{ }^{\circ} \mathrm{C}$ on slants of yeast mannitol agar and liquid cultures were grown in the defined medium described by Vincent (1962). The formation of nodules on Arachis hypogea var. TG-3 was used to verify the infectivity of the Rhizobium strains. Escherichia coli and Bacillus subtilis were grown in nutrient broth. Bacterial cell populations were determined using a PetroffHauser bacterial counting chamber.

Purification of peanut agglutinin. PNA was purified from seeds of Arachis hypogea var. TG-3. The initial phase of the purification procedure was as described by Lotan et al. (1975). The $\left(\mathrm{NH}_{4}\right)_{2} \mathrm{SO}_{4}$ precipitated PNA was loaded on a DEAE-cellulose column (Whatman DE-52;25.0 $\times 0.85 \mathrm{~cm}$ ), which had been equilibrated with phosphate buffer $(0.05 \mathrm{M}, \mathrm{pH} 7.2)$ and was eluted with a linear gradient of $\mathrm{NaCl}(100 \mathrm{ml}, 0$ to $1 \mathrm{M})$ in the same buffer. Fractions eluting at $15.0 \mathrm{~mm}-\mathrm{NaCl}$ and showing haemagglutination of neuraminidase-treated group B + red blood cells (Lotan et al., 1975) were pooled $(2.5 \mathrm{ml})$ and lyophilized. The material was then dissolved in phosphate-buffered saline [PBS; $0.05 \mathrm{M}$-phosphate buffer in $0.9 \%(\mathrm{w} / \mathrm{v}) \mathrm{NaCl}, \mathrm{pH} \mathrm{7.2]}$ and partitioned on a Sephadex G-150 column $(23 \times 1.2 \mathrm{~cm})$ by eluting with PBS. Fractions were monitored for absorbance at $280 \mathrm{~nm}$ and for haemagglutinating activity. Purified PNA was collected in a single symmetrical peak. The molecular weight of the PNA was determined by comparison with the elution volumes of standard proteins (bovine $\gamma$-globulin, bovine serum albumin, ovalbumin, lactoperoxidase, malate dehydrogenase, lactate dehydrogenase, chymotrypsinogen) on Sephadex G-150 $(52 \times 1.5 \mathrm{~cm})$.

Preparation of FITC-labelled PNA. The method of Udenfriend (1962) was followed in preparing PNA labelled with fluorescein isothiocyanate (FITC-PNA). To $1 \mathrm{mg}$ PNA (obtained by dissolving in PBS the lyophilized material after DEAE-cellulose column chromatography during the PNA purification procedure) in $10 \mathrm{ml} 0.05 \mathrm{M}$-sodium bicarbonate buffer ( $\mathrm{pH} \mathrm{9.0)}$ containing 0.1 M-D-galactose, $0.05 \mathrm{mg}$ FITC was added and stirred for $2 \mathrm{~h}$ at room temperature. The FITC-PNA complex formed was dialysed against 11 PBS (three changes) at $5{ }^{\circ} \mathrm{C}$ and the complex was concentrated by lyophilization.

Preparation of ${ }^{125}$ I-labelled PNA. Radioactively labelled PNA ( ${ }^{125}$ I-PNA) was prepared by the chloramine-T oxidation procedure for labelling proteins (Sela et al., 1971). Carrier-free ${ }^{125} \mathrm{I}\left[1 \mathrm{mCi}\right.$, sp.act. $14 \mathrm{mCi} \mu \mathrm{g}^{-1}$ (518 MBq $\mu \mathrm{g}^{-1}$ ), The Radiochemical Centre, Amersham] was added as NaI to $200 \mu \mathrm{l}$ PBS containing adequate PNA (5.0 mg ml-1 , obtained after the DEAE-cellulose column chromatography stage of the PNA purification procedure). Iodination was initiated by adding $5 \mu \mathrm{l}(25 \mu \mathrm{g})$ chloramine-T in water. The reaction, which was allowed to proceed in an ice bath for $60 \mathrm{~s}$, was stopped by adding $10 \mu \mathrm{l}(100 \mu \mathrm{g})$ sodium metabisulphite. The iodinated PNA was separated from unreacted and damaged PNA and other proteins by filtration on Sephadex G-150 $(23 \times 1 \cdot 2 \mathrm{~cm})$. Fractions showing peak haemagglutinating activity were pooled and the free ${ }^{125}$ I was removed either by dialysis against PBS or, preferably, by the use of Dowex anion exchange resin (chloride form, 1-X8, 50/100; a few mg of the resin was added to the pooled fraction and after $15 \mathrm{~min}$ at $5^{\circ} \mathrm{C}$ the resin was removed by centrifugation for $5 \mathrm{~min}$ at $5000 \mathrm{~g}$ ). Absence of free ${ }^{125 \mathrm{I}}$ in the ${ }^{125} \mathrm{I}-\mathrm{PNA}$ 
sample was confirmed by electrophoresis on cellulose acetate strips in $0.05 \mathrm{M}$-phosphate buffer (pH $8 \cdot 6)$. The ${ }^{125}$ I-PNA was diluted with unlabelled PNA to give solutions (in PBS) containing $200 \mu \mathrm{g}$ PNA $\mathrm{ml}^{-1}$ and having $3 \times 10^{5}$ c.p.m. ml ${ }^{-1}$. The specific activity of the PNA product was $1.43 \mu \mathrm{Ci} \mathrm{mg}^{-1}$.

FITC-PNA binding. FITC-PNA $(25 \mu \mathrm{g})$ was added to $2 \times 10^{7}$ cells suspended in $1.0 \mathrm{ml} \mathrm{PBS}$ and incubated at $25^{\circ} \mathrm{C}$ for $30 \mathrm{~min}$. Cells were pelleted by centrifuging at $12000 \mathrm{~g}$ for $15 \mathrm{~min}$ and resuspended in PBS. FITC-labelling was examined using a fluorescence miscroscope (Carl Zeiss, Oberkochen, W. Germany) equipped with phase contrast objectives. The phase objectives helped in confirming fluorescent material as bacteria.

${ }^{125}$ I-PNA binding to unwashed rhizobia. Rhizobial cultures ( 64 h-old) were harvested by centrifugation for $10 \mathrm{~min}$ at $12000 \mathrm{~g}$ and suspended in PBS at $2 \times 10^{\circ} \mathrm{cells} \mathrm{ml}^{-1}$. Saturation curves for ${ }^{125}$ I-PNA binding to rhizobial populations indicated that $10 \mu \mathrm{g}^{125} \mathrm{I}-\mathrm{PNA} \mathrm{ml} \mathrm{m}^{-1}$ was adequate. In the binding experiments reported here, $20 \mu \mathrm{g}{ }^{125} \mathrm{I}-\mathrm{PNA}$ was added to $1 \mathrm{ml}$ of the suspension and incubated for $30 \mathrm{~min}$ at $37^{\circ} \mathrm{C}$. The suspension was then centrifuged at $4{ }^{\circ} \mathrm{C}(12000 \mathrm{~g} ; 10 \mathrm{~min})$ and the supernatant was discarded. The radioactivity of the pellet was determined to obtain the initial value for the bound ${ }^{125}$ I-PNA. The pellet was then washed four times in PBS to determine the release of latelled material into the supernatant. The pooled supernatants and the pellet were counted for radioactivity on a Radioimmune Assay Counter (Electronics Division, Bhabha Atomic Research Centre, Bombay, India) equipped with a sodium iodide-thallium crystal scintillation system.

${ }^{125}$ I-PNA binding to washed rhizobia. Washed cells were prepared by repeating resuspension and centrifugation $\left(12000 \mathrm{~g} ; 10 \mathrm{~min}, 4^{\circ} \mathrm{C}\right)$ in PBS four times. Washed suspensions $\left(2 \times 10^{9}\right.$ cells $\left.\mathrm{ml}^{-1}\right)$ were incubated at $37^{\circ} \mathrm{C}$ with ${ }^{125} \mathrm{I}-\mathrm{PNA}\left(20 \mu \mathrm{g} \mathrm{m} \mathrm{m}^{-1}\right)$ for periods ranging from 1 to $60 \mathrm{~min}$ followed by centrifugation $(12000 \mathrm{~g})$ at $4^{\circ} \mathrm{C}$. The radioactivity of the pellet was determined as described above.

Precipitation of exopolysaccharide-125 I-PNA complex. Suspensions of Rhizobium B.TG-3 were centrifuged $\left(12000 \mathrm{~g} ; 10 \mathrm{~min}, 4^{\circ} \mathrm{C}\right)$ and the pellets were washed four times by resuspension in PBS followed by centrifugation. The pooled supernatants were vacuum dialysed and then dialysed twice against 11 PBS. The material after dialysis was designated exopolysaccharide (EXP). The sugar content of EXP was determined by the anthrone test (Ashwell, 1957). To $500 \mu \mathrm{g}$ (glucose equivalents) EXP in $1 \mathrm{ml} \mathrm{PBS,} \mathrm{20 \mu g}{ }^{125}$ I-PNA was added and the material was incubated at $37^{\circ} \mathrm{C}$ for $30 \mathrm{~min}$. The polysaccharide-PNA complex was then precipitated in acetone according to the procedure of Sutherland \& Wilkinson (1971). Solubility of noncomplexed ${ }^{125}$ I-PNA in acetone was ascertained by the following procedure: $20 \mu \mathrm{g}^{125} \mathrm{I}-\mathrm{PNA} \mathrm{ml}^{-1}$ in water was diluted with acetone to give a final concentration of $70 \%(\mathrm{v} / \mathrm{v})$ acetone. This material was processed as for EXP precipitation. The material was then centrifuged at $12000 \mathrm{~g}$ to ascertain the formation of precipitate. In addition, the material was filtered through a Millipore filter $(0 \cdot 2 \mu \mathrm{m}$ pore size $)$ and the filter and filtrate were separately examined for radioactivity.

Isolation of lipopolysaccharide-125I-PNA complex. Rhizobium B.TG-3 cultures were washed four times in PBS, resuspended in PBS at $10^{10}$ cells $\mathrm{ml}^{-1}$ and incubated with $20 \mu \mathrm{g}^{125} \mathrm{I}-\mathrm{PNA} \mathrm{ml^{-1 }}$ at $37^{\circ} \mathrm{C}$ for $30 \mathrm{~min}$. The bacteria were collected by centrifugation and the lipopolysaccharide (LPS)- ${ }^{125}$ I-PNA complex was extracted using hot phenol according to the procedure of Maier \& Brill (1978). The quantity of LPS-125I-PNA complex extracted was estimated in the radioimmune assay counter. In some experiments, after phenol extraction the aqueous phase (phenol-free) was lyophilized. The dried material was dissolved in water and placed on to a column of Dowex anion exchange resin (1-X8, 50/100, acetate form). The column was eluted with water to yield LPS material designated LPS fraction A. The column was then eluted with $1 \mathrm{M}-\mathrm{NaCl}$ to yield the acidic LPS designated LPS fraction B. The sugar content of the LPS fractions was determined by the anthrone test. The competitive PNA binding property of these fractions was then assessed by their ability to inhibit, as well as reverse, haemagglutination.

Inhibition of haemagglutination by rhizobial lipopolysaccharide. Fresh human blood (type B) from one of us (A.A.B.), collected in the presence of heparin $\left(100\right.$ units $\left.\mathrm{ml}^{-1}\right)$, was washed three times in $0.9 \%(\mathrm{w} / \mathrm{v}) \mathrm{NaCl}$ and resuspended to give $2 \%(\mathrm{v} / \mathrm{v})$ blood cell concentration. The suspension was treated with 20 units neuraminidase $\mathrm{ml}^{-1}$ for $60 \mathrm{~min}$ at $37^{\circ} \mathrm{C}$ and then washed four times with PBS. PNA (20 $\mu \mathrm{g}$ in $0 \cdot 2 \mathrm{ml}$ PBS) was incubated for $45 \mathrm{~min}$ in the presence of either $100 \mathrm{~mm}$-galactose, lactose, galactosamine, or $30 \mu \mathrm{g}$ of the $\mathrm{A}$ or $B$ fraction of rhizobial LPS. The resulting mixture was stirred with $0.1 \mathrm{ml}$ of the neuraminidase-treated erythrocytes and incubated for $60 \mathrm{~min}$ at $37^{\circ} \mathrm{C}$. The suspension was then examined for agglutination. In some experiments, the neuraminidase-treated erythrocytes were preagglutinated by incubation for 45 min with $20 \mu \mathrm{g} \mathrm{PNA} \mathrm{ml}^{-1}$. The preagglutinated material $(0 \cdot 2 \mathrm{ml})$ was then incubated further for $60 \mathrm{~min}$ in the presence of $30 \mu \mathrm{g}$ of the LPS fraction or $100 \mathrm{~mm}$-sugar to test for reversion to free cell suspension. 


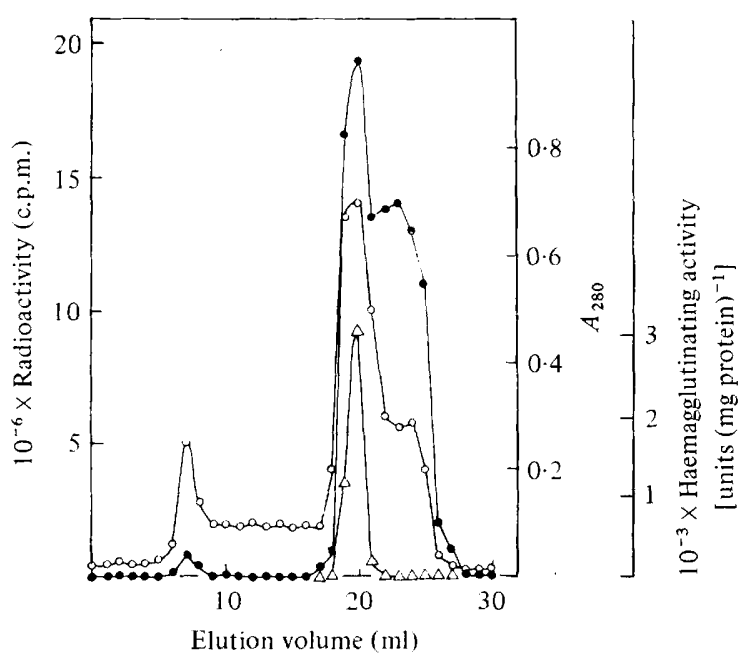

Fig. 1. Pattern of elution from Sephadex G-150 of ${ }^{125}$ I-labelling and haemagglutinating activity of partially purified PNA: $\bigcirc, A_{280} ; O$, radioactivity; $\triangle$, haemagglutinating activity.

\section{RESULTS AND DISCUSSION}

The peanut lectin was eluted as a symmetrical peak from the Sephadex G-150 column $(52 \times 1.5 \mathrm{~cm})$. Its molecular weight, estimated from the comparative elution sequence of the PNA with standard proteins (see Methods), was nearly 112000 , i.e. close to the value of 110000 previously determined (Lotan et al., 1975) for another peanut variety from data on sedimentation, diffusion and gel filtration.

When the ${ }^{125}$ I-labelled proteins, obtained by iodination of the active portion separated on the DEAE-cellulose column, were resolved on Sephadex G-150, the haemagglutinating activity was located in a narrow symmetrical peak (Fig. 1). The purified PNA was about 60-fold more active than crude extracts.

Rhizobium strains B.TG-3 and $5 a$, which nodulate peanut roots, bound both FITC- and ${ }^{125}$ I-labelled PNA. Rhizobium japonicum and $R$. meliloti, which do not nodulate peanut, and the non-nitrogen-fixing bacteria E. coli and B. subtilis, did not bind the labelled lectin. These results, demonstrating the specificity of PNA binding to the rhizobia capable of nodulating peanut, agree with similar legume-Rhizobium specificity found previously for soybean (Bohlool \& Schmidt, 1974; Bhuvaneswari et al., 1977) and clover (Dazzo et al., 1978). Only Bhuvaneswari et al. (1977) had previously demonstrated specificity using radioactively labelled lectin.

Washing in PBS removed polysaccharides from the cell surface. After four such washings, no more sugar was released. Moreover, when the washed bacterial suspensions were treated for $10 \mathrm{~min}$ in boiling water and then centrifuged, the resulting supernatant did not contain sugar, indicating that rhizobial EXP could be completely dissolved from the cell surface by washing in PBS.

A major portion of the bound radioactive lectin on the rhizobia could also be removed by washing the suspensions in PBS (Table 1) indicating the EXP nature of the binding sites. The EXP content of Rhizobium B.TG-3 increased with the age of the culture (Fig. 2). After incubation of the EXP with ${ }^{125}$ I-PNA, most of the added radioactivity could be precipitated with $70 \%(\mathrm{v} / \mathrm{v})$ acetone showing that the EXP complexed with ${ }^{125}$ I-PNA. When ${ }^{125 I-P N A}$ was subjected to the same process in the absence of EXP, no radioactive complex could be detected as a precipitate, either in the form of a sediment on centrifugation or on filtration. The amount of ${ }^{125}$ I-PNA complexed with EXP and the sugar content of the EXP preparation 
Table 1. Effect of washing on ${ }^{125}$ I-PNA binding to rhizobia

Details of experiments are given in Methods. Values in parentheses are percentages with respect to the number of molecules initially bound.

\begin{tabular}{|c|c|c|}
\hline \multirow[b]{2}{*}{${ }^{125}$ I-PNA } & \multicolumn{2}{|c|}{$\begin{array}{c}10^{-3} \times \text { No. of }{ }^{125} \text { I-PNA molecules } \\
\text { bound per Rhizobium cell }\end{array}$} \\
\hline & Rhizobium B.TG-3 & Rhizobium $5 a$ \\
\hline $\begin{array}{l}\text { ly bound } \\
\text { hed after washing } \\
\text { ved by washing }\end{array}$ & $\begin{array}{c}34 \cdot 7(100) \\
7 \cdot 5(22) \\
27 \cdot 7(80)\end{array}$ & $\begin{array}{l}44 \cdot 2(100) \\
14 \cdot 7(33) \\
28 \cdot 9(66)\end{array}$ \\
\hline
\end{tabular}

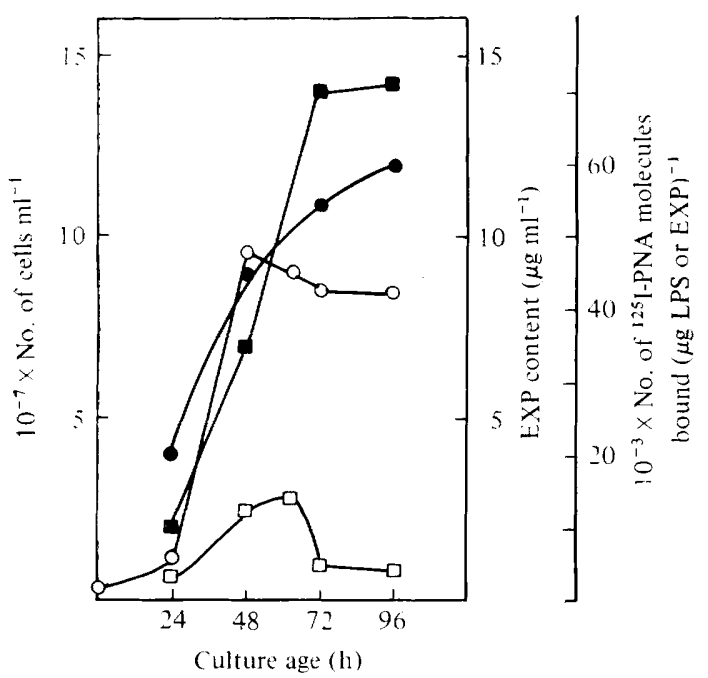

Fig. 2

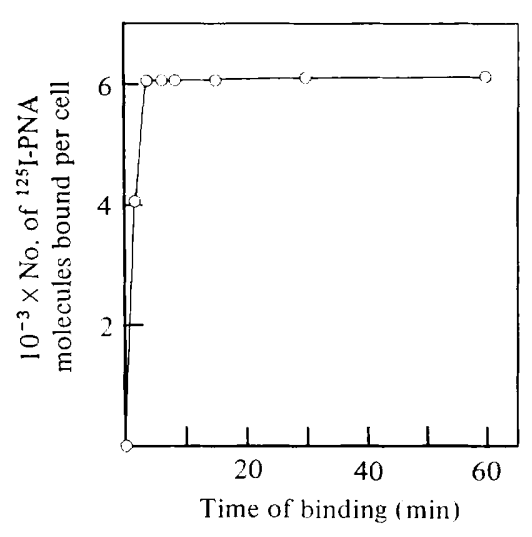

Fig. 3

Fig. 2. Binding of ${ }^{225}$ I-labelled PNA to exopolysaccharide (EXP, $\mathbf{a}$ ) and lipopolysaccharide (LPS, $\square$ ) of Rhizobium B.TG-3. The EXP content $(O)$ and cell numbers $(O)$ are also shown. All polysaccharide concentrations are expressed as glucose equivalents.

Fig. 3. Time-course of binding of ${ }^{125}$ I-labelled PNA to washed suspensions of Rhizobium B.TG-3.

followed the same pattern with the age of the culture. These results clearly demonstrate binding of PNA to the exopolysaccharides of the rhizobia.

Although washing in PBS removed most of the bound lectin, a significant amount of the ${ }^{125}$ I-PNA was still bound to the rhizobia (Table 1). Since washing removed EXP, the remaining activity was probably due to binding of ${ }^{125}$ I-PNA to LPS. Transfer of EXP-bound ${ }^{125}$ I-PNA to LPS may occur while LPS is newly exposed during washing. However, at $4{ }^{\circ} \mathrm{C}$ (the temperature maintained during washing), the risk of re-equilibration of ${ }^{125}{ }^{2}-\mathrm{PNA}^{\prime}$ is minimized. For instance, agglutination of neuraminidase-treated red blood cells took nearly $20 \mathrm{~min}$ at $4{ }^{\circ} \mathrm{C}$ as against $3 \mathrm{~min}$ required at $37^{\circ} \mathrm{C}$.

The capacity of LPS to bind PNA is clearly demonstrated by the fact that Rhizobium B.TG-3 cultures showed significant binding of ${ }^{125}$ I-PNA even after removal of EXP by four washings in PBS (Fig. 3). The time course showed that added lectin was rapidly bound to the washed bacteria. The bound activity could not be removed by further washing in PBS but was extractable with hot phenol (Fig. 2). The binding of phenol-extractable lectin decreased markedly in old cultures.

LPS extracted with hot phenol, after removal of EXP by washing in PBS, could be separated into two fractions, A and B, using a Dowex column. Fraction A inhibited haemagglutination of human erythrocytes, an effect which was also caused by galactose, 
lactose and galactosamine. Moreover, fraction $\mathrm{A}$ and the sugars caused unequivocal reversion of preagglutinated erythrocytes into free cell suspensions. Fraction B also inhibited haemagglutination, but was somewhat less effective.

Our results indicate that there are dual binding sites for PNA on the rhizobial cells: the EXP and the LPS. The discrepancies in the earlier literature, assigning either EXP (capsular polysaccharide) (Dazzo \& Brill, 1977), LPS (Wolpert \& Albersheim, 1976; Maier \& Brill, 1978) or a transient component on the rhizobial cell surface (Bhuvaneswari et al., 1977) as the receptor site for lectin binding, may have been due to differences in the experimental conditions employed. Age of culture and conditions for processing the bacterial cultures for assay would greatly influence the results (Fig. 2). Although Bhuvaneswari et al. (1977) concluded that soybean lectin binding sites are transient components on the rhizobial cell surface, they found that the soybean lectin binding curves were biphasic and hinted at the possibility that two types of receptor structures might exist on the rhizobial cell surface. Several features of our results are consistent with the presence of dual receptor sites on the rhizobia which nodulate peanut. The quantitative results on the binding of ${ }^{125}$ I-PNA demonstrate that EXP are the major lectin binding sites on these rhizobia; LPS are probably secondary sites and the observation that lectin binds readily to LPS after removal of EXP may be of ecological significance. EXP are known to be secreted and the quantity of EXP available as receptors on the bacterial cell surface may become negligible depending on the bacterial growth phase and the micro-environment. Under such circumstances LPS may play a major role in the legume-Rhizobium recognition process. It may also be that EXP helps in casual binding of the rhizobia to the root wall lectin and that the more specific binding is achieved by LPS.

We are grateful to Dr R. S. Mani of Isotope Group, BARC, for providing the facilities, to Miss Meera Subramanian for the help in preparing ${ }^{125} \mathrm{I}$-labelled peanut lectin and to Dr R.S. Kamat, Haffkine Institute, Bombay, for facilities and help with fluorescence microscopy.

\section{REFERENCES}

AsHWELL, G. (1957). Colorimetric analysis of sugars. Methods in Enzymology 3, 73-105.

BAUER, W. D. (1977). Lectins as determinants of specificity in legume-rhizobium symbiosis. In Genetic Engineering for Nitrogen Fixation, pp. 283-297. Edited by A. Hollaender. New York: Plenum Press.

Bhuvaneswari, T. V., Pueprke, S. G. \& Bauer, W. D. (1977). Role of lectins in plant-microorganism interactions. I. Binding of soybean lectin to rhizobia. Plant Physiology 60, 486-491.

Bohlool, B. B. \& Schmidt, E. L. (1974). Lectins: a possible basis for specificity in the Rhizobium legume root nodule symbiosis. Science $\mathbf{1 8 5}$, 269-271.

Calvert, H. E., Lalonde, M,, Bhuvaneswari, T. V. \& BAuER, W. D. (1978). Role of lectins in plant-microorganism interactions. IV. Ultrastructural localization of soybean lectin binding sites on Rhizobium japonicum. Canadian Journal of Microbiology 24, 785-793.

Chen, A. T. \& Phillips, D. A. (1976). Attachment of Rhizobium to legume roots as the basis for specific interactions. Physiologia plantarum 38, 83-88.

DAzzo, F. B. \& BRILL, W. J. (1977). Receptor site on clover and alfalfa roots for Rhizobium. Applied Microbiology 33, 132-136.
Dazzo, F. B. \& Hubbell, D. H. (1975a). Crossreactive antigens and lectin as determinants of symbiotic specificity in the Rhizobium-clover association. Applied Microbiology 30, 1017-1033.

Dazzo, F. B. \& Hưbell, D. H. (1975b). Concanavalin A: lack of correlation between binding to Rhizobium and specificity in the Rhizobiumlegume symbiosis. Plant and Soil 43, 713-717.

Dazzo, F. B., Napoli, C. A. \& Hubbell, D. H. (1976). Adsorption of bacteria to roots as related to host specificity in the Rhizobium-clover symbiosis. Applied and Environmental Microbiology 32, 166-171.

Dazzo, F. B., YaNKe, W. E. \& BRILl, W. J. (1978). Trifoliin: a Rhizobium recognition protein from white clover. Biochimica et biophysica acta 539, 276-286.

Kamat, A. S. \& Kumta, U. S. (1974). Predominance of Bacillus in radurized tropical shrimps (Penaeus indicus and Metapenaeus affinis). LebensmittelWissenschaft und Technologie 7, 279-284.

Lotan, R., Skutelsky, E., Danon, D. \& Sharon, N. (1975). The purification, composition and specificity of the anti-T lectin from peanut (Arachis hypogea). Journal of Biological Chemistry 250, 8518-8523.

MahajaN, S. K. \& DatTA, A. R. (1977). Nature of recombinants produced by the $\operatorname{Rec} B C$ and the 
Rec $\mathbf{F}$ pathways in Escherichia coli. Nature, London 266, 652-653.

MAIER, R. J. \& BRILL, W. J. (1978). Involvement of Rhizobium japonicum $\mathrm{O}$ antigen in soybean nodulation. Journal of Bacteriology 133, 1295-1299.

Patil, S. H. (1973). Trombay groundnut selections for increased oil content and yield. Indian Journal of Agricultural Sciences 43, 370-376.

Púl, P. S., Pueprke, S. G., Hymowitz, T. \& Orf, J. H. (1978). Soybean lines lacking the 120,000dalton seed lectin. Science 200, 1277-1279.

Sela, B. A., Lis, H., Sharon, N. \& Sachs, L. (1971). Quantitation of $N$-acetyl-D-galactose-like site on the surface membrane of normal and transformed mammalian cells. Biochimica et biophysica acta 249, 564-568.
Sutherland, I. W. \& Wilkinson, J. F. (1971). Chemical extraction methods of microbial cells. Methods in Microbiology 5B, 345-384.

UDENFRIEND, S. (1962). Fluorescence Assay in Biology and Medicine, p. 221. New York: Academic Press.

VINCENT, J. M. (1962). Influence of calcium and magnesium on the growth of Rhizobium. Journal of General Microbiology 28, 653-663.

Wolpert, J. S. \& Albersheim, P. (1976). Hostsymbiont interactions. I. The lectins of legumes interact with the O-antigen-containing lipopolysaccharide of their symbiont rhizobia. Biochemical and Biophysical Research Communications 70, 729-737. 